\title{
Effective Electron Transfer of Self-Assembled Redox-Active Peptide with an Affinity for Glucose Oxidase
}

\author{
Shu Taira, Kenji Yokoyama ${ }^{1}$, Daisaku Kaneko², \\ Natsuki Yamaguchi and Tatsuro Endo ${ }^{3, *}$ \\ Department of Bioscience, Fukui Prefectural University, Eiheiji, Fukui 910-1195, Japan \\ ${ }^{1}$ School of Bioscience and Biotechnology, Tokyo University of Technology, \\ 1404-1 Katakuramachi, Hachioji, Tokyo 192-0982, Japan \\ ${ }^{2}$ Kyushu Institute of Technology, 1-1 Sensui, Tobata, Kitakyushu, Fukuoka 804-0015, Japan \\ ${ }^{3}$ Graduate School of Engineering, Osaka Prefecture University, \\ 1-1 Gakuen, Naka, Sakai, Osaka 599-8531, Japan
}

(Received December 22, 2014; accepted January 21, 2015)

Key words: redox-active peptide, glucose oxidase, biosensor, Fmoc solid-phase peptide synthesis, self-assembled monolayer

We describe the synthesis of a self-assembled redox-active peptide (RAP), which has an affinity for flavin adenine dinucleotide (FAD) as an electron acceptor, as well as its electrochemical characterization as a biosensor. We synthesized $\mathrm{N}$-ferrocene and C-cysteine-terminated RAP (L-H-P-P-M-D-F-H-L-A-M-T-R-EAhx-C) by Fmoc solidphase peptide synthesis. The C-cysteine-terminated RAP was immobilized on a gold electrode by the self-assembled monolayer method. It exhibited a stable electrochemical response after several potential sweeps. The FAD-captured RAP recognized glucose oxidase on the electrode surface. Current increased as the concentration of glucose increased. The self-assembled RAP-immobilized electrode effectively measures the electron transfer between the substrate and the enzyme; thus, it is suitable as a biosensor material.

\section{Introduction}

Electrochemical detection biosensors have been widely studied for applications in the medical field, ${ }^{(1,2)}$ food control, ${ }^{(3,4)}$ and environmental protection. ${ }^{(5)}$ By using electrochemical detection biosensors, the experimental setup and devices can be simplified and miniaturized easily with micro-electromechanical systems. These biosensors can be developed as industry-based biosensors. However, previously reported

"Corresponding author: e-mail: endo@chem.osakafu-u.ac.jp 
electrochemical detection biosensors have insufficient electron transfer efficiency. Because efficient transfer is important, the electrons should be acted on near the electrode surface in the sample solution. To improve the electron transfer efficiency for biosensing applications, better experimental setups using methods such as microfabrication ${ }^{(6,7)}$ have been reported. Previously, we performed the electrochemical characterization of a biosensor using redox active materials in sample solutions, ${ }^{(8,9)}$ which increased the electron transfer efficiency, although it was not sufficient for the high-sensitivity detection of target molecules.

In this study, we focused on the bioaffinity between glucose oxidase (GOx) and a redox-active peptide (RAP) to improve electron transfer and chemical immobilization using self-assembled monolayers (SAMs). We selected a peptide sequence with high affinity for flavin adenine dinucleotide (FAD) as an electron acceptor in GOx using Fmoc solid-phase peptide synthesis. The selected peptide redox-active site was also modified with ferrocene on the $\mathrm{N}$-terminal and a cysteine residue on the $\mathrm{C}$-terminal to immobilize it on a gold electrode as a SAM (Fig. 1).

We performed electrochemical characterization to demonstrate the suitability of RAP with an affinity for GOx for biosensing applications. Cyclic voltammetry of the enzyme electrode showed the current dependence on glucose concentration, confirming that RAP allows effective electron transfer to the electrode. This bioaffinity sensing using peptide would be applied to selective analysis in crude samples.

\section{Experimental Section}

\subsection{Synthesis of RAP by Fmoc solid-phase peptide synthesis}

Amino acids (AAs), $\alpha$-aminohexanoic acid ( $\alpha$-hex), ferrocene carboxylic acid and GOx from Aspergillius niger (XS, 25000 units/g) were purchased from Sigma-Aldrich (USA). A peptide synthesizer (PSSM-8; Shimadzu, Japan) was used. We synthesized

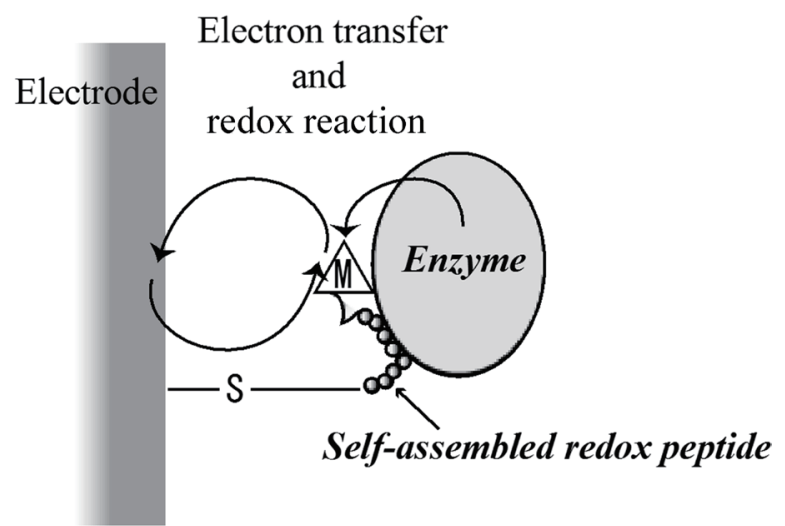

Fig. 1. Schematic illustration of redox peptide biosensor. S: thiol group; M: mediator. 
eight RAPs that were selected by a combinatorial chemistry technique. The C-terminus of the resin-immobilized AA sequence and the Fmoc-protected N-terminus of the next AA in the sequence were coupled by 1-ethyl-3-(3-dimethylaminopropyl)-carbodiimide hydrochloride and N-hydroxysuccinimide. The Fmoc group was cleaved under mild acidic conditions from the trailing AA. Subsequently, the other Fmoc-AAs were coupled under the same conditions. The N-terminal AA residue was lysine to allow modification with ferrocene carboxylic acid. After the peptide sequence was synthesized, RAP was cleaved from the resin. The crude RAP product was separated on a Shiseido Capcell Pak column using acetonitrile: 0.1\% TFA (40:60) by high-performance liquid chromatography. The sequence of RAP was confirmed by mass spectrometry.

\subsection{Electrochemical characterization of the RAP SAM}

The gold electrode was soaked in phosphate buffer $(50 \mathrm{mM}, \mathrm{pH} 7.0)$ containing RAP $(1 \mathrm{mg} / \mathrm{mL})$ for $60 \mathrm{~min}$ to immobilize RAP via SAM formation. A three-electrode configuration was used. A SAM-based RAP electrode, a platinum wire, and $\mathrm{Ag} / \mathrm{AgCl} /$ $\mathrm{KCl}$ were used as the work, auxiliary, and reference electrodes, respectively. Cyclic voltammetry $(\mathrm{CV})$ was carried out in a deoxygenated phosphate buffer $(10 \mathrm{mM}, \mathrm{pH} 7.0)$ with a computer-controlled potentiostat (CV-50W; BAS, USA) at a scan rate of 1 or $5 \mathrm{mV} / \mathrm{s}$.

\section{Results and Discussion}

\subsection{Synthesis of RAP}

The dissociation constants $\left(K_{\mathrm{d}}\right)$ vs GOx of these peptides were evaluated by surface plasmon resonance. We chose the sequence L-H-P-P-M-D-F-H-L-A-M-T-R for RAP because it had the smallest $K_{\mathrm{d}}(1.1 \mathrm{E}-04 \mathrm{M})$ (Table 1). The elution of RAP was detected at $\mathrm{m} / \mathrm{z} 2236.3$ as protonated RAP, which was in good agreement with the theoretical value.

Table 1

Redox-active peptide.

\begin{tabular}{lccccc}
\hline \multirow{2}{*}{ Sequence } & $\begin{array}{c}\text { Anodic peak } \\
\text { potential }\end{array}$ & & & $\begin{array}{c}\text { Dissociation } \\
\text { constant }\end{array}$ \\
\cline { 2 - 6 } & $E_{\mathrm{pa}}(\mathrm{mV})$ & $I_{\mathrm{d}}(\mu \mathrm{A})$ & $I_{\mathrm{k}}(\mu \mathrm{A})$ & $I_{\mathrm{k}} / I_{\mathrm{d}}$ & $K_{\mathrm{d}}(\mathrm{M})$ \\
\hline No. 1) FcK(Fc) H P P M D F H K A M T R & 519 & 0.540 & 11.3 & 20.9 & $1.1 \mathrm{E}-04$ \\
(No. 2) FcK(Fc) A P W P S P T H Y L K D & 500 & 0.4698 & 7.00 & 14.9 & $4.3 \mathrm{E}-04$ \\
(No. 3) FcK(Fc) Q I P L M K G P G Y M Y & 491 & 0.140 & 3.45 & 24.4 & $2.7 \mathrm{E}-04$ \\
(No. 4) FcK(Fc) Y S A H A S A H A S A H & 514 & 0.0328 & 0.223 & 6.78 & $7.8 \mathrm{E}-01$ \\
(No. 5) FcK(Fc) G Y T D H G T D H G D T & 523 & 0.491 & 4.66 & 10.0 & $3.2 \mathrm{E}-01$ \\
(No. 6) FcK(Fc) L V D H D T S N I P G S & 515 & 0.526 & 3.83 & 7.27 & $4.9 \mathrm{E}-04$ \\
(No. 7) FcK(Fc) E H K A K H S K H Y H K & 520 & 0.189 & 5.16 & 27.3 & $3.3 \mathrm{E}-04$ \\
(No. 8) FcK(Fc) E S D E S D E S D S S D & 485 & 0.309 & 0.645 & 2.08 & $2.4 \mathrm{E}-04$ \\
\hline All-t
\end{tabular}

All C-termini were added to the lysine residue owing to the modification of ferrocene. 


\subsection{Electrochemical characteristics of RAP in a homogenous system}

RAP showed a typical electrochemical response in a homogeneous system. After $10 \mathrm{CV}$ scans, stable cyclic voltammograms were obtained. The peak-to-peak potential separation $\left(\Delta E_{\mathrm{p}}\right)$ of RAP was almost $100 \mathrm{mV}$, and the wave was not reversible because it was a homogenous system. The catalytic electrochemistry of GOx with RAP was also investigated. The RAP-enhanced catalytic electrochemical response in the presence of glucose $(10 \mathrm{mM})$ and $\mathrm{GOx}$ in a buffer solution, $I_{\mathrm{k}} / I_{\mathrm{d}}$, was 6.5 at $E_{\mathrm{pa}}=528 \mathrm{mV}$ (Fig. 2). $E_{\mathrm{pa}}$ was delayed compared with that of ferrocene carboxylic acid, where $E_{\mathrm{pa}}$ occurs at 400 $\mathrm{mV}$ owing to the homogenous system.

\subsection{Electrochemical characteristics of RAP SAM}

RAP was immobilized as a SAM on the gold electrode through the thiol group of the cysteine residue. When the electrode was held at a high potential, a physically adsorbed RAP became more hydrophilic because of ferrocene and was removed from the electrode surface, leaving only the RAP SAM. Moreover, the electrode-modified RAP showed a stable response after $10 \mathrm{CV}$ scans. When the RAP is immobilized on an electrode surface via SAM, we would expect to observe a reversible wave, but here we did not observe such a response. The oxidation and reduction peaks were observed at +528 and $+450 \mathrm{mV}$ (vs $\mathrm{Ag} / \mathrm{AgCl}$ ), respectively. The $\alpha$-hex linker between ferrocene and peptide may have created a complex interface; thus, delayed electron transfer occurred.

The catalytic electrochemistry of GOx with a RAP-based electrode and glucose was investigated. A catalytic current was observed upon the addition of glucose at $E_{\mathrm{p}}(610$ $\mathrm{mV}$ ), although the current plateaued at $20 \mathrm{mM}$ glucose (Fig. 3). In a control experiment
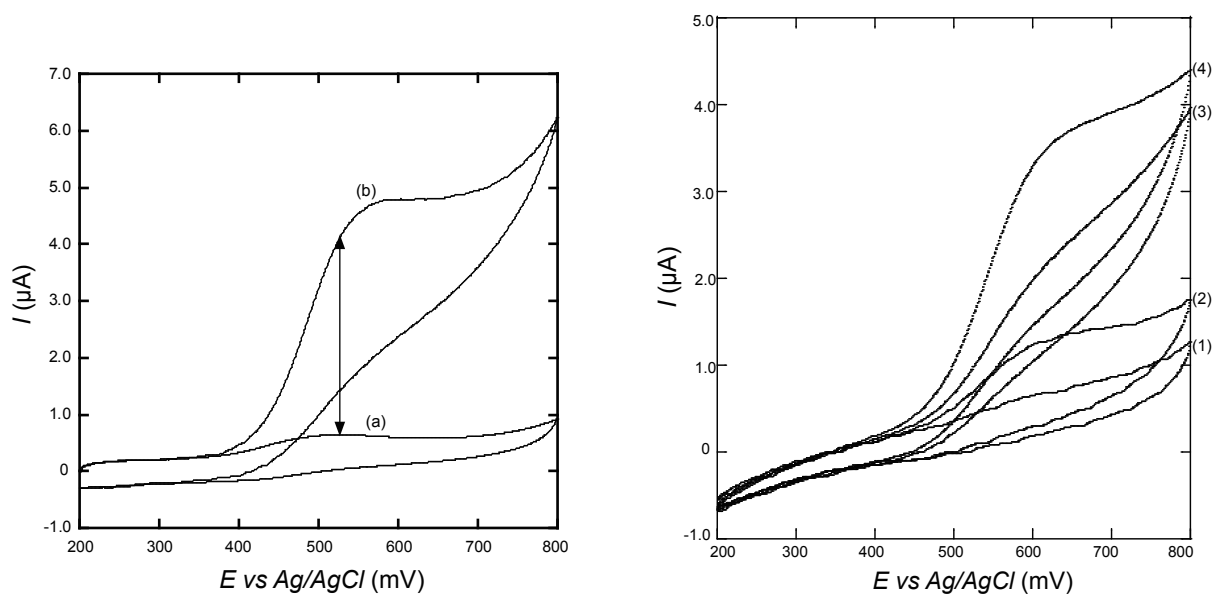

Fig. 2 (left). Catalytic electrochemistry of the redox-active peptide electrode in a homogeneous system. CV was performed at a scan rate of $5 \mathrm{mV} / \mathrm{s}$ in $100 \mathrm{mM}$ phosphate buffer (pH 7.0) (a) without and (b) with $10 \mathrm{mM} \mathrm{D}(+)$-glucose.

Fig. 3 (right). Voltammograms of the RAP SAM modified gold electrode in the presence of 1.0 $\mu \mathrm{M}$ GOx. CV was performed at a scan rate of $1 \mathrm{mV} / \mathrm{s}$ in $0.1 \mathrm{M}$ phosphate buffer ( $\mathrm{pH} 7.0)$ and (1) 0 , (2) 2.0 , (3) 5.0, and (4) $20.0 \mathrm{mM}$ glucose. 
using a random peptide sequence, no catalytic response was observed. Thus, the SAMbased RAP, which has bioaffinity to GOx, could retain GOx on the electrode surface and indicated a catalytic response. The peak current for the catalytic response showed a positive shift compared with that without the glucose substrate. For the $\Delta E_{\mathrm{p}}$ of the RAP SAM modified gold electrode, the value $(610 \mathrm{mV})$ increased compared with that of the homogeneous system $(80 \mathrm{mV})$ at the same scan rate. The RAP SAM on the electrode showed thin-layer characteristics. ${ }^{(10)}$

\section{Conclusions}

We have constructed a peptide electrode covalently modified with a redox active compound. RAP has affinity for GOx, indicating the effective electron transfer between GOx and the RAP-immobilized electrode. The catalytic response depended on the glucose concentration from 0 to $20 \mathrm{mM}$. The RAP-immobilized electrode is a suitable biosensor for GOx and could be used for other enzymes by altering the peptide sequence.

\section{Acknowledgements}

This research was supported by a SUNBOR Grant and the LOTTE Foundation to ST and that to DK.

\section{References}

1 S. Yarar and E. Karakus: Artif. Cells, Nanomed. Biotechnol. DOI: 10.3109/21691401.2014.962746 (2014).

2 N. Xuan Viet, M. Chikae, Y. Ukita, K. Maehashi, K. Matsumoto, E. Tamiya, P. Hung Viet and Y. Takamura: Biosens. Bioelectron. 42 (2013) 592.

3 D. Xiang, L. Yin, J. Ma, E. Guo, Q. Li, Z. Li and K. Liu: Analyst 140 (2015) 644.

4 N. S. Ismail, Q. H. Le, H. Yoshikawa, M. Saito and E. Tamiya: Electrochim. Acta 146 (2014) 98.

5 K. Yamada, C. T. Kim, J. H. Kim, J. H. Chung, H. G. Lee and S. Jun: PLoS One 9 (2014) e105767.

6 T. Endo, C. Ueda, H. Kajita, N. Okuda, S. Tanaka and H. Hisamoto: Microchim. Acta 180 (2013) 929.

7 T. Endo, H. Takizawa, Y. Yanagida and T. Hatsuzawa: IEEJ Trans. Sens. Micromach. 133 (2013) 374.

8 S. Taira, E. Tamiya and K. Yokoyama: Electrochemistry 69 (2001) 940.

9 S. Taira, E. Tamiya, K. Yokoyama and E. Ichiishi: Sens. Mater. 20 (2008) 309.

10 X. Huang, L. J. Doneski and M. J. Wirth: Anal. Chem. 70 (1998) 4023. 